\title{
Respiratory presentations to acute services at a tertiary hospital in South Africa
}

\author{
V Ngah, ${ }^{1}$ BNS, PGD, MScMed; P Maud, ${ }^{1}$ MB ChB; N Baines, ${ }^{1}$ BSc; \\ R Mistry, ${ }^{2} \mathrm{MB}$ ChB, DCH (SA), Dip Allergy (SA), Dip HIV Man (SA), MBA; N Schrueder, ${ }^{3} \mathrm{MB}$ ChB, FCP (SA); \\ C F N Koegelenberg, ${ }^{1}$ MB ChB, MMed (Int), FCP (SA), FRCP (UK), Cert Pulm (SA), PhD; E M Irusen, ${ }^{1}$ MB ChB, FCP (SA), FCCP, PhD; \\ K Mortimer, ${ }^{4} \mathrm{MB}$ BChir, FRCP, PhD; B W Allwood, ${ }^{1} \mathrm{MB}$ BCh, FCP (SA), Cert Pulm (SA) MPH, PhD
}

\author{
${ }^{1}$ Division of Pulmonology, Department of Medicine, Faculty of Medicine and Health Sciences, Stellenbosch University and Tygerberg Hospital, \\ Cape Town, South Africa \\ ${ }^{2}$ Hospital Management, Tygerberg Hospital, Cape Town, South Africa \\ ${ }^{3}$ Division of General Medicine, Department of Medicine, Faculty of Medicine and Health Sciences, Stellenbosch University and Tygerberg \\ Hospital, Cape Town, South Africa \\ ${ }^{4}$ Department of Clinical Sciences, Liverpool School of Tropical Medicine, Liverpool, UK
}

Corresponding author: V Ngah (verangah@sun.ac.za)

\begin{abstract}
Background. Respiratory diseases account for $>10 \%$ of the global burden of disease when measured in disability-adjusted life-years. The burden of chronic respiratory diseases (CRDs) increases as the world's population ages, with a much greater increase in low- to middleincome countries.

Objectives. To characterise and quantify the reasons for acute respiratory presentations to the acute care services at a tertiary hospital in Cape Town, South Africa.

Methods. A cross-sectional descriptive study was conducted. Casualty registers and electronic record databases were reviewed to determine the diagnoses of consecutive patients attending the casualty unit from May 2019 to January 2020.

Results. A total of 1053 individual patients presented with a primary respiratory diagnosis. Fewer than $10 \%$ of admissions were from outside the Cape Town metropole, while $>60 \%$ were from the subdistrict immediately adjacent to the hospital. Of all patients, $8.3 \%$ were readmitted at least once within the 9-month study period. Six hundred and forty-three (61.1\%) of the patients presented with non-CRDs. The main reasons for presentation in these patients were pulmonary tuberculosis (PTB) $(n=224 ; 21.3 \%)$, other infections including lower respiratory tract infections, pneumonia and bronchitis $(n=272 ; 25.8 \%)$, and cancer $(n=140 ; 13.3 \%)$. Haemoptysis was seen in $9.8 \%$ of all patients, mainly explained by post-tuberculosis lung disease (PTLD) (37.9\%) and PTB (36.9\%). Of the patients, 410 (38.9\%) had an underlying CRD, with chronic pulmonary obstructive disease (COPD) being the most common $(n=192 ; 18.2 \%)$, followed by PTLD ( $n=88$; $8.5 \%)$ and asthma $(n=52 ; 5.1 \%)$.

Conclusions. Over a 9-month period, acute respiratory presentations to a tertiary hospital were mainly for primary/secondary level of care indications, highlighting disparity in accessing tertiary services. COPD and PTLD predominated among CRDs, while infections and cancers were common. A high readmission rate was found for several diseases, suggesting the potential for targeted interventions to prevent both admissions and readmissions and reduce acute hospital utilisation costs.
\end{abstract}

S Afr Med J 2021;111(11):1104-1109. https://doi.org/10.7196/SAMJ.2021.v111i11.15711

Respiratory diseases make a substantial contribution to the global burden of disease. They account for $>10 \%$ of the world's burden of disease, measured in disability-adjusted life-years (DALYs). ${ }^{[1]}$ Over 1 billion people suffer from acute or chronic respiratory conditions worldwide, and 4 million people die prematurely from chronic respiratory disease (CRD) every year. ${ }^{[2-4]}$ Asthma, chronic obstructive pulmonary disease (COPD), acute lower respiratory tract infections, pulmonary tuberculosis (PTB) and lung cancer are some of the causes of severe illness and death, even though they have preventable risk factors. ${ }^{[2,5]}$ As the world's population ages, the burden from CRDs will continue to increase, and there is likely to be a much greater burden in low- to middle-income countries (LMICs), ${ }^{[2,4,6]}$ including many countries in sub-Saharan Africa.

In South Africa (SA), national mortality data in 2016 showed that respiratory disease was the fifth leading cause of death, accounting for $9.4 \%$ of all deaths. ${ }^{[7]}$ However, this figure excludes PTB and malignancies, which fall into different categories. Tuberculosis (TB) was the overall leading cause of natural death, pneumonia being 7 th, while chronic lower respiratory diseases accounted for $2.8 \%$ of all deaths and were the 10th leading cause of natural death in 2016. ${ }^{[7]}$

Although PTB is successfully treated in $>80 \%$ of patients, many have permanent lung damage termed post-tuberculosis lung disease (PTLD), which can be worsened by multidrug-resistant PTB, delayed diagnosis and non-compliance with treatment. ${ }^{[7-10]}$ In SA, the incidence of PTB in 2018 was 301 per 100000 (95\% confidence interval 215 - 400), and the number of patients with PTLD requiring acute medical services is not known. ${ }^{[11]}$ A study in Uganda showed that $30 \%$ of patients attending a tertiary referral TB clinic presented with PTLD, while $12 \%$ of patients attending the chest and respiratory clinic had PTLD. ${ }^{[12]}$

Although respiratory diseases are a major contributor to the global burden of disease, the prevalence and causes of respiratory disease in sub-Saharan Africa are not well known, with concerns that they are underdiagnosed in LMICs. Additionally, acute hospital presentations account for disproportionate healthcare utilisation costs in CRD care ${ }^{[12-14]}$ yet the causes of and contributors to these respiratory presentations are not clear in SA. 


\section{Objectives}

To characterise and quantify the reasons for acute respiratory presentations to the acute care service at the tertiary Tygerberg Hospital (TBH) in Cape Town, SA. We also explored the disease presentation in relation to geographical locations of the patients.

\section{Methods}

\section{Study design}

This was a cross-sectional descriptive study.

\section{Setting}

The setting was the acute medical admissions unit of the 1380 bed TBH. TBH serves as a tertiary referral hospital for four health subdistricts in the City of Cape Town Metropolitan Municipality (namely the Tygerberg, Khayelitsha, and Eastern and Northern subdistricts) as well as three non-metropolitan districts (Cape Winelands, Overberg, and parts of the West Coast district), with an estimated drainage population of $>3.4$ million people. ${ }^{[15]} \mathrm{TBH}$ is the ultimate referral hospital for 2 regional hospitals and 22 district hospitals ( 3 of which are in the Cape Town metropole), as well as the network of primary care facilities (clinics) they serve. ${ }^{[16]}$ The total population for each district and subdistrict used in calculations was obtained from the 2020 Western Cape Province population data. ${ }^{[17]}$

\section{Participants}

All patients with an acute respiratory presentation, including adolescents, were eligible for inclusion. Patients admitted for a non-respiratory problem, but known to have an underlying chronic respiratory condition, were not included. Patients referred to TBH for admission from outlying hospitals are registered in the acute medical casualty department, prior to obtaining a bed in a ward, and were therefore included.

\section{Data collection}

Daily casualty patient registers were used to identify patients presenting for admission, and electronic record databases were retrospectively reviewed to determine the individual patient's ultimate diagnosis as made by the attending doctor. Audit information was entered directly into a database, the final diagnosis was manually determined, and International Statistical Classification of Diseases and Related Health Problems (ICD) coding was applied. Underlying chronic respiratory conditions were documented and reasons for presenting to the acute services recorded. For the purposes of the study, the term 'respiratory infection' as a reason for presentation was a defined as a composite of the documented diagnoses of 'lower respiratory tract infection', 'bronchitis' and 'pneumonia', but excluded PTB.

\section{Study size}

Our aim was to include all patients with respiratory presentations over a 12-month period. However, owing to the start of the COVID19 pandemic, we eventually settled on a 9-month period and a total of 1053 patients.

\section{Data analysis}

Normally distributed continuous data were presented as means with corresponding standard deviations (SDs), while discrete data were presented as numbers and percentages. Data were presented graphically in tables and bar charts. The $\chi^{2}$ test was used to determine statistically significant differences between groups depending on the normality of data (normality was tested using the Shapiro-Wilk test for normality plots).

\section{Ethical considerations}

The study was approved by the Stellenbosch University Human Research Ethics Committee (ref. no. N20/02/026) and by the hospital research committee.

\section{Results \\ Participants}

Between May 2019 and January 2020, a total of 1053 patients presented to the acute admissions unit of $\mathrm{TBH}$ with a primary respiratory complaint. The study was concluded prematurely in January 2020 because of COVID-19, as routine services were de-escalated and results would therefore be biased. The mean (SD) age of the patients was 51.6 (17.3) years, and there were similar numbers of females $(n=526$; $49.9 \%)$ and males ( $n=527 ; 50.1 \%)$.

Patients were received from five districts in the Western Cape Cape Winelands (5.5\%), Garden Route (0.1\%), Overberg (1.6\%), West Coast (1.3\%), and City of Cape Town (91.5\%) - and from 22 health subdistricts across the five districts. Most patients were from the Tygerberg subdistrict $(n=631 ; 65.4 \%)$, followed by the Eastern $(n=174$; $17.5 \%)$ and Khayelitsha $(n=87 ; 9.0 \%)$ subdistricts within the City of Cape Town. Geographical locations relative to TBH are presented in Fig. 1.

\section{Diagnoses}

Of patients presenting with a respiratory complaint, 410 (38.8\%) were found to have an underlying CRD ( $n=210$ females; $51.3 \%$ ), with a mean (SD) age of 54.6 (15.6) years. COPD was the most common CRD. The commonest causes of presentation in patients with COPD were acute exacerbations (88.6\%), respiratory infections including pneumonia (3.8\%), and haemoptysis (2.8\%). Patients with COPD were significantly older than those with asthma $(p<0.001)$. Eightyeight patients (8.4\%) presented with PTLD. The commonest reasons for presentation in PTLD were haemoptysis (44.3\%), infection including pneumonia (22.7\%), and progression of the PTLD (13.6\%). Patients with PTLD were significantly younger than those with COPD $(p<0.001)$. Thirty-nine patients $(3.7 \%)$ had a primary diagnosis of pulmonary hypertension (PHT). Of these, 6 had primary arterial PHT (World Health Organization group 1), 5 had PHT secondary to heart disease (group 2), 12 had PHT secondary to lung disease (group 3), and 16 had chronic thromboembolic PHT (group 4); of the group 4 patients, 9 were likely to have had acute pulmonary emboli.

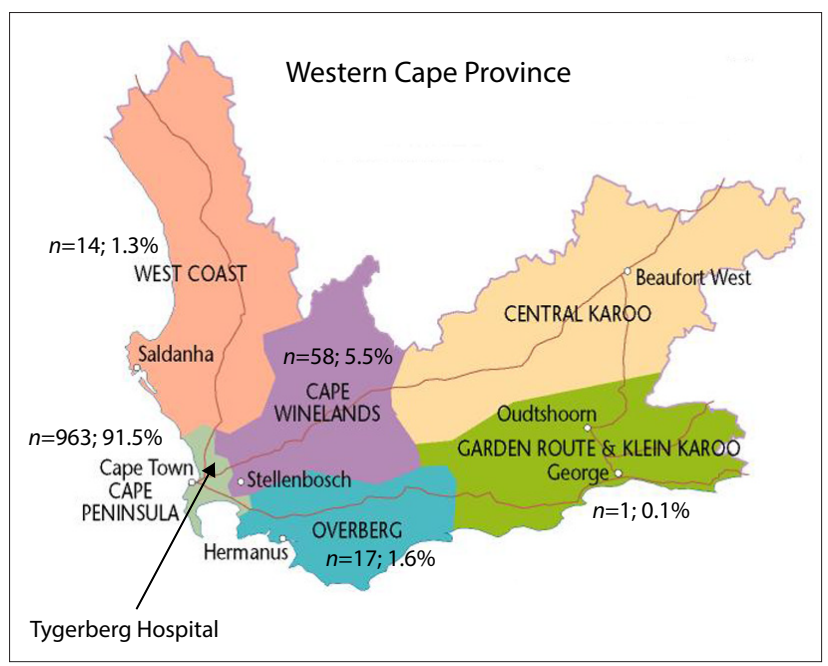

Fig. 1. Numbers and proportions of patients presenting for acute medical services from the five health districts. 
There were 644 patients $(61.2 \%)$ who were not found to have an underlying CRD (mean (SD) age 49.6 (18) years). The main reasons for presentation for these patients were respiratory infections, i.e. lower respiratory tract infections, pneumonia and bronchitis (25.8\%), РTB (21.3\%) and cancer (13.3\%); 7 patients had a primary diagnosis classified as 'other'. A female predominance was observed for asthma and PHT, with the proportion of female patients with asthma statistically greater than that for COPD ( $p=0.008$ ), while PTB and lung cancer, as well as COPD, showed a male predominance.

Table 1 shows the gender and ages of patients with respiratory diseases, while the proportions and reasons for presentation of each CRD are presented in Fig. 2.

\section{Haemoptysis}

Of the 1053 patients seen at the respiratory unit, 103 (9.8\%) presented with haemoptysis. The mean (SD) age of these patients was 44 (15.7) years. The main underlying cause of haemoptysis was PTLD (37.9 \%) and PTB (36.9\%). The mean (SD) age of PTB patients was 37.3 (14.7) years, while that for patients with PTLD was 47.1 (11.4) years. Other underlying causes for haemoptysis were infection (6.8\%), cancer (6.9\%), PHT (1.9\%), COPD (5.8\%), interstitial lung disease (ILD) (1.9\%) and asthma (1.9\%). Seventy-seven (74.8\%) were resident in the City of Cape Town metropole, with 35 (34.0\%) from the Tygerberg, 16 (15.5\%) from the Eastern, 12 (11.7\%) from the Khayelitsha and $9(8.7 \%)$ from the Northern subdistricts.

\section{Readmissions}

Eighty-seven patients $(8.3 \%)$ were readmit- ted within the 9-month study period, with a total of 221 readmission records. The highest number of readmissions was for COPD (73 readmissions for 33 patients), followed by repeated infections (38 readmissions for 25 patients). PTLD patients had 28 admissions (9 patients), cancer patients had 23 readmissions (8 patients), PTB patients had

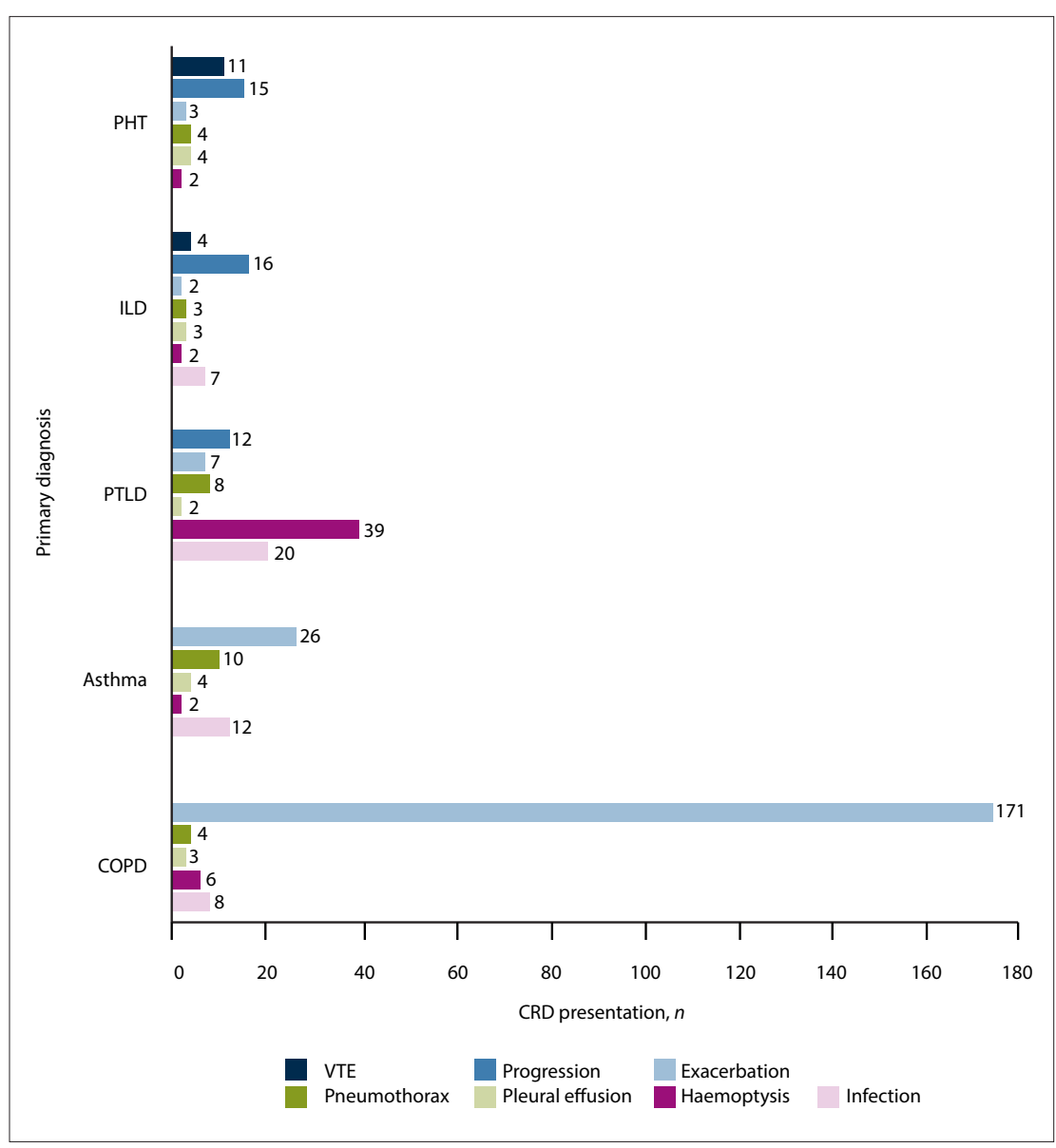

Fig. 2. Primary diagnoses of patients with $C R D$ and reasons for presentation to acute medical services. $(C R D=$ chronic respiratory disease; $P H T=$ pulmonary hypertension; $I L D=$ interstitial lung disease; $P T L D=$ post-tuberculosis lung disease $; C O P D=$ chronic obstructive pulmonary disease; $V T E=$ venous thromboembolism.)

\begin{tabular}{|c|c|c|c|c|c|c|c|}
\hline Disease & $\begin{array}{l}\text { Total } \\
\left(N=1053, n(\%)^{*}\right.\end{array}$ & $\begin{array}{l}\text { Age (years), } \\
\text { mean (SD) }\end{array}$ & $\begin{array}{l}\text { Females } \\
(N=526), n(\%)^{\dagger}\end{array}$ & $\begin{array}{l}\text { Age (years), } \\
\text { females, mean (SD) }\end{array}$ & $\begin{array}{l}\text { Males } \\
(N=527), n(\%)^{\dagger}\end{array}$ & $\begin{array}{l}\text { Age (years), } \\
\text { males, mean } \\
\text { (SD) }\end{array}$ & $\begin{array}{l}p \text {-value for } \\
\text { age difference } \\
\text { between } \\
\text { genders }\end{array}$ \\
\hline \multicolumn{8}{|l|}{ Known CRD } \\
\hline COPD & $192(18.2)$ & $61.2(12)$ & 85 (44.3) & $63.4(13.5)$ & $107(55.7)$ & $60.5(10.6)$ & 0.08 \\
\hline PTLD & $88(8.4)$ & $47(13)$ & $37(42.0)$ & 44.7 (13.9) & $51(58.0)$ & $48.5(12.04)$ & 0.18 \\
\hline Asthma & $54(5.1)$ & $43(19)$ & $36(69.2)$ & $44.6(19.4)$ & $16(30.8)$ & $38.2(17.3)$ & 0.29 \\
\hline ILD & $37(3.5)$ & $53.8(14)$ & $22(59.5)$ & $51.6(16.7)$ & $15(40.5)$ & $57(8.5)$ & 0.19 \\
\hline PHT & $40(3.8)$ & $53.7(15.5)$ & $30(75.0)$ & $50(16)$ & $10(25.0)$ & $61.6(12.1)$ & 0.06 \\
\hline Total & $410(38.9)$ & $54.6(15.6)$ & $210(51.3)$ & $53.9(17.3)$ & $199(48.7)$ & $55.4(13.6)$ & 0.32 \\
\hline \multicolumn{8}{|l|}{ Non-CRD } \\
\hline РTB & $225(21.3)$ & $39.8(15.3)$ & $104(46.2)$ & $36.9(14.9)$ & $121(53.8)$ & $42.2(15.2)$ & 0.01 \\
\hline Infections & $272(25.8)$ & $52.9(18.4)$ & $150(55.1)$ & $58.9(19.1)$ & $122(44.9)$ & $50.4(17.4)$ & 0.06 \\
\hline Cancer & $140(13.3)$ & $59.5(12.1)$ & $57(40.7)$ & $62.1(11.9)$ & $83(59.3)$ & $57.6(11.9)$ & 0.03 \\
\hline
\end{tabular}


21 readmissions (9 patients), haemoptysis patients had 20 readmissions (11 patients), and asthma patients had 8 readmissions (6 patients). The lowest numbers of readmissions were for PHT (6 readmissions, 2 patients) and ILD (4 readmissions, 3 patients). Of the readmissions, $70.9 \%$ of patients were from the Tygerberg subdistrict, 8.1\% each from Khayelitsha and the Eastern subdistrict, $5.8 \%$ from the Northern subdistrict. $2.3 \%$ each from the Drakenstein and Mitchell's Plain subdistricts, and 1.2\% each from the Swartland and Western subdistricts. The proportion of patients readmitted by respiratory diagnosis is shown in Table 2 and Fig. 3.

\section{Diagnosis by health districts}

The City of Cape Town health district (Fig. 4) accounted for $91.5 \%$ ( $n=963$ ) of the patients, with majority being from the Tygerberg subdistrict $(n=631 ; 65.5 \%)$. The number of presentations per 100000 population was 86.4 for the Tygerberg, 19.7 for the Khayelitsha, 24.7 for the Eastern, 2.2 for the Klipfontein, 1.6 for the Mitchell's Plain, 9.8 for the Northern, 0.8 for the Southern and 1.3 for the Western subdistricts. For the Tygerberg subdistrict patients, infections were the most common primary reason for presentation $(n=171 ; 27.1 \%)$ The mean (SD) age for these patients was 54 (18) years. COPD was found in 157 (24.9\%) (29.5\%) of the patients in Tygerberg (mean (SD) age 59 (11.2) years)

\section{Discussion}

This cross-sectional study of consecutive presentations to the acute care unit of a large urban SA hospital over a 9-month period (pre-COVID-19) provides new insights into these presentations. Although the hospital is designated as a tertiary referral hospital for an extensive geographical area of $>3.4$ million people, $<10 \%$ of admissions were from outside the metropole, with most admissions (59.9\%) being from the area immediately adjacent to the hospital. Approximately a quarter of the patients (25.8\%) were diagnosed with infection, and among patients with no CRD, one-third had PTB and one-fifth lung cancer. COPD and PTLD were the most common CRDs, together accounting for almost $70 \%$ of CRD admissions. Almost one in 10 presentations were for haemoptysis, and despite the short study period, readmission rates for CRDs, as well as haemoptysis, were high.

In keeping with global trends and previous local data, ${ }^{[16]}$ COPD was the most common CRD (46.9\%), with acute exacerbations accounting for $89.1 \%$ of these presentations. ${ }^{[17]}$ Within the 9-month study time frame, $17.2 \%$ of COPD patients were readmitted, with 38 readmissions per 100 patients seen. Although high, this readmission rate probably underestimates the annual readmission rate $^{[18]}$ owing to the shortening of study period to 9 months because of the COVID-19 pandemic. However, this finding provides insight into the missed opportunity acute COPD presentations afford to intervene to reduce future morbidity and costs in CRD care.

PTLD, an under-recognised cause of global CRD, ${ }^{[9]}$ accounted for $21.5 \%$ of all CRD admissions, with haemoptysis $(44.3 \%)$ and

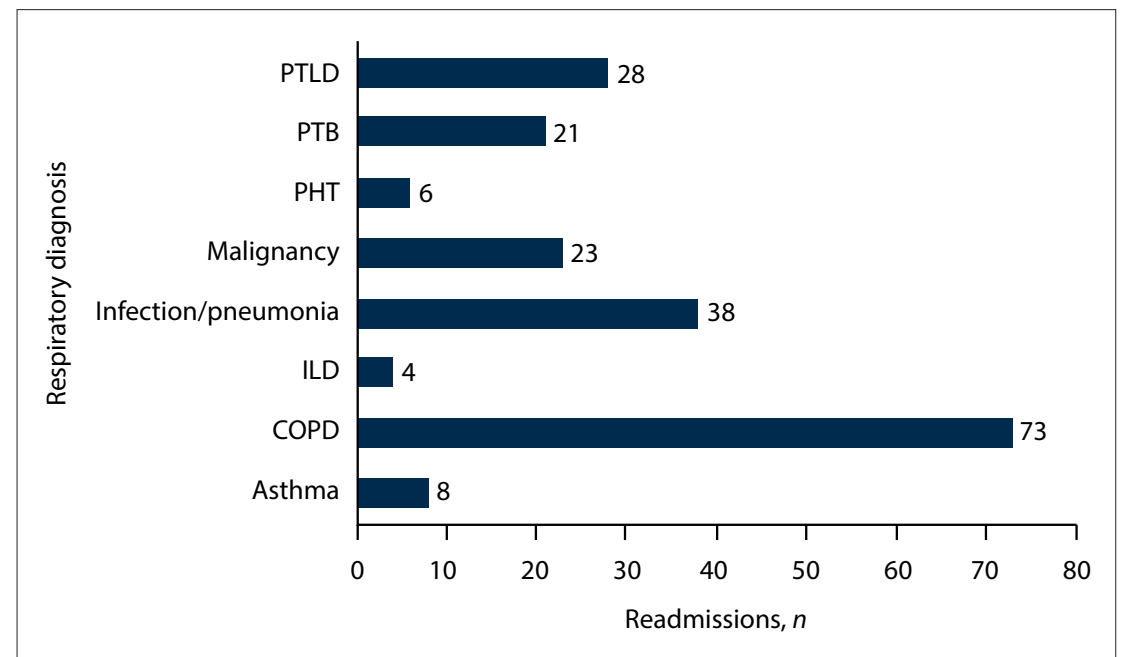

Fig. 3. Number of readmissions by respiratory diagnosis. (PTLD = post-tuberculosis lung disease; $P T B=$ pulmonary tuberculosis; $P H T=$ pulmonary hypertension; $I L D=$ interstitial lung disease; $C O P D=$ chronic obstructive lung disease.)

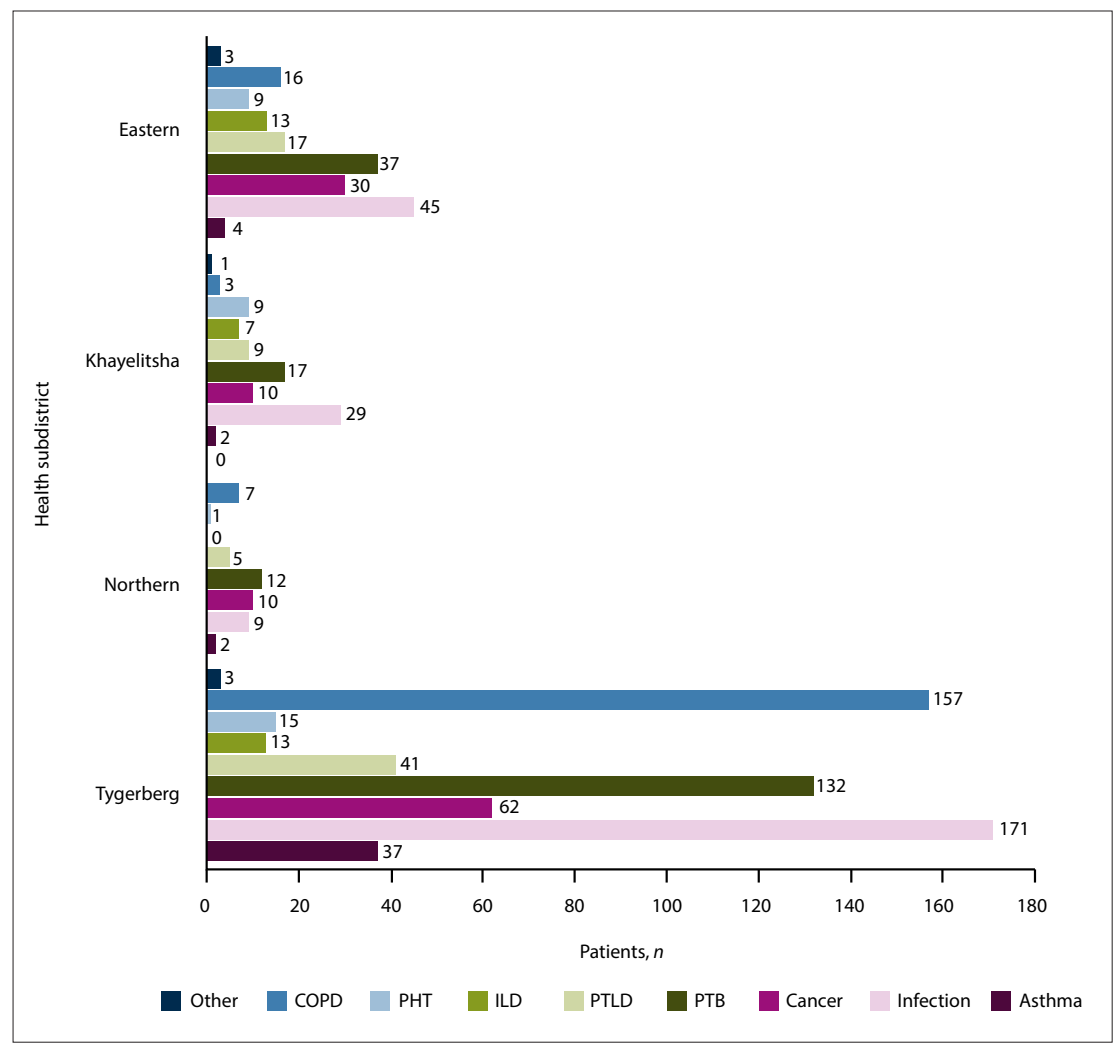

Fig. 4. Respiratory diagnoses of patients residing in the City of Cape Town accessing acute medical services, by health subdistrict of residence. (COPD = chronic obstructive lung disease; $P H T=$ pulmonary hypertension; ILD = interstitial lung disease; $P T L D=$ post-tuberculosis lung disease; $P T B=$ pulmonary tuberculosis.) 
Table 2. Readmission of patients within the 9-month study period, by respiratory diagnosis

\begin{tabular}{llllll}
\hline $\begin{array}{l}\text { Respiratory } \\
\text { diagnosis }\end{array}$ & $\begin{array}{l}\text { Total patients } \\
\text { presenting, } \boldsymbol{N}\end{array}$ & Readmissions, $\boldsymbol{n}$ & $\begin{array}{l}\text { Patients with } \\
\text { readmission, } \boldsymbol{n}\end{array}$ & $\begin{array}{l}\text { Proportion of patients } \\
\text { readmitted, } \%\end{array}$ & $\begin{array}{l}\text { Readmissions per } \mathbf{1 0 0} \\
\text { patients, } \boldsymbol{n}\end{array}$ \\
\hline COPD & 192 & 73 & 33 & 17.2 & 38.0 \\
PTLD & 88 & 28 & 9 & 10.2 & 31.8 \\
Asthma & 54 & 8 & 6 & 11.5 & 15.4 \\
ILD & 37 & 4 & 3 & 8.1 & 10.8 \\
PHT & 40 & 6 & 2 & 5 & 15 \\
PTB & 225 & 21 & 9 & 4 & 9.3 \\
Infections & 272 & 25 & 8 & 9.2 & 14 \\
Cancer & 140 & 23 & 11 & 5.7 & 16.4 \\
Haemoptysis & 103 & 20 & & & \\
COPD = chronic obstructive lung disease; PTLD = post-tuberculosis lung disease; ILD = interstitial lung disease; PHT = pulmonary hypertension; PTB = pulmonary tuberculosis.
\end{tabular}

respiratory infections including pneumonia $(22.7 \%)$ being the primary reasons for acute healthcare service utilisation. The male preponderance of PTLD mirrors that of acute TB, ${ }^{[19]}$ with age symmetry between the genders. Although patients with PTLD were significantly younger than those with COPD, they were significantly older than patients with PTB, and had a notable readmission rate of 31.8 per 100 patient admissions within the 9 months. This again emphasises the under-appreciated yet harmful impact PTLD has on patient DALYs, which incredibly is not currently included in global estimates of DALYs resulting from PTB. ${ }^{[20,21]}$

Haemoptysis, sufficient to warrant presentation, occurred in a young population and was the reason for presentation in $9.8 \%$ of all respiratory presentations to our institution. Unlike Western cohorts, where lung cancer is a prominent cause of haemoptysis, ${ }^{[22,23]}$ a total of $82.9 \%$ of haemoptysis presentations were due to PTLD or PTB, with the latter group being significantly younger than the former. This age discordance again highlights the distal footprint that TB leaves on the lungs of many individuals, who return years later with complications of their PTLD. The readmission rate for haemoptysis patients was high, with $10.7 \%$ reporting readmissions in the 9-month study frame, giving a readmission rate of 19.4 per 100 patients. The recurrent morbidity that can occur with this life-threatening presentation can be forgotten and remains a difficult clinical problem in certain individuals with inoperable disease. ${ }^{[24,25]}$

The burden of lung cancer was high and accounted for $13.3 \%$ of all respiratory presentations in our population, but with a discordance in age between the genders, with females being on average 5 years older than men, a significant difference $(p=0.03)$. This finding may reflect local smoking patterns, with females tending to smoke less than their male counterparts. ${ }^{[26]}$ The overall age was similar to comparable cohorts internationally, with the average age of lung cancer presentation reported as 50 - 64 years in Denmark, Germany and the Netherlands, ${ }^{[27]}$ but may reflect the selection or referral bias of this particular cohort. We found few comparative data on lung cancer incidence or prevalence in sub-Saharan Africa.

PTB, traditionally diagnosed at primary care level, accounted for $21.3 \%$ of all respiratory presentations, and these patients comprised a young population. There was insufficient detail collected to determine the reasons why these patients presented to acute medical casualty and not primary care services, but the three most likely reasons were severe disease warranting hospital admission (suggesting delayed access to care), inappropriate referral pathways, and difficulty in securing the diagnosis.

Surprisingly, despite the study time frame spanning the Southern Hemisphere winter and spring, asthma accounted for only $5.1 \%$ of acute presentations, with the population being predictably younger (with a higher proportion of females) than COPD patients, and 11.5\% requiring more than one admission. $\mathrm{SA}$ is reported to have one of the highest asthma rates in the world, ${ }^{[28]}$ making it difficult to fully explain the low proportion of asthma patients observed in this study, especially considering the size of the total draining population.

The observed referral patterns for TBH may raise concern. As the only tertiary referral hospital for these subdistricts, the hospital should receive patients from four of the health subdistricts in the Cape Town metropole (Eastern, Khayelitsha, Northern and Tygerberg subdistricts), as well as three extra-metropolitan areas (Cape Winelands, Overberg, and portions of West Coast districts), However, the hospital provides a primary care service for the Tygerberg subdistrict, as well as secondary services for this and the Eastern subdistrict. Our results indicate that the hospital received 91.5\% of presentations from the City of Cape Town, with $65.5 \%$ of all patients from the Tygerberg health subdistrict (Fig. 4). Expressed as a function of population size, there were more than three times the number of presentations from the Tygerberg district, per 100000 population, than any other district. On the assumption that most patients admitted for COPD, asthma, infections and tuberculosis should be managed in primary or secondary hospital services, up to $70.4 \%$ of all admissions to our hospital were unlikely to require a tertiary care facility, while $67.1 \%$ of these were from the immediately adjacent Tygerberg subdistrict. This finding is likely to have two major implications. Firstly, the high burden of primary- and secondarylevel admissions may hamper TBH's role as the only dedicated tertiary service for 3.4 million people. Further study of the disease burden at other facilities is needed to confirm this. Secondly, patients admitted to a facility for a primary- and secondary-level diagnosis, but where tertiary services are available, may be advantaged in terms of the level and quality of care that they have access to (e.g. a full lung physiology laboratory, daily bronchoscopy slates, and subspecialist pulmonologist on-site consultations if required) compared with patients from other districts and subdistricts, purely for geographical reasons. This situation needs to be further researched, and solutions should be found to facilitate improved access to acute tertiary services for a broader geographical population, or alternatively dissemination of those services to other centres to ensure more equitable access to the resources.

\section{Study limitations}

Almost all patients with acute admissions and acute referrals enter our hospital through the acute admissions unit, and a strength of our study was that we manually assessed all admissions over 
a 9-month period for respiratory presentations and ascertained the final diagnosis without reliance on recorded ICD-10 coding. However, the data are limited by the usual difficulties of retrospective data collection, and reliance on diagnoses as documented by a doctor. Furthermore, resource constraints did not allow more detailed collection of disease information (e.g. subtyping of ILDs and PHT), clinical details (e.g. smoking history, HIV status, etc.) or 9-month mortality outcomes. Also, as this study included presentations from only one tertiary hospital, these findings may not necessarily be applicable to other sub-Saharan hospitals or populations.

\section{Conclusions}

These data provide a unique description of the range of respiratory presentations to acute tertiary medical services in Cape Town, SA. Most of our acute respiratory admissions were unlikely to need tertiary-level services, highlighting the primary/secondary-level role that the hospital is playing. Approximately $40 \%$ of patients had an underlying CRD, mainly COPD and PTLD, with PTB, respiratory tract infection, haemoptysis and lung cancers being common reasons for presentation. The high readmission rate for several diseases requires further study, as targeted interventions designed to prevent readmission may have a significant impact on cost and service provision.

\section{Declaration. None.}

Acknowledgements. We thank the medical and nursing staff of TBH, in particular those in the Department of Medicine and those working in the medical admissions unit, for their tireless work in caring for their patients. Author contributions. VN, PM, NB, BWA, CFNK and EMI were involved in the conceptualisation, data collection and analysis, writing and review of the manuscript. RM and NS were involved in the writing and review of the manuscript. KM was involved in the review of the manuscript.

Funding. We thank the NIHR Global Health Research Unit on Lung Health and Tuberculosis in Africa at LSTM (IMPALA) for helping to make this work possible. In relation to IMPALA (grant no. 16/136/35) specifically, IMPALA was commissioned by the National Institute for Health Research (NIHR) Global Health Research (GHR) using UK aid from the UK government. The views expressed in this publication are those of the authors and not necessarily those of the NIHR or the Department of Health and Social Care.

Conflicts of interest. None.

1. Forum of International Respiratory Societies. The Global Impact of Respiratory Disease. 2nd ed. Sheffield, UK: European Respiratory Society, 2017.

2. Ferkol T, Schraufnagel D. The global burden of respiratory disease. Ann Am Thorac Soc 2014;11 (3):404 406. https://doi.org/10.1513/annalsats.201311-405ps

3. Bousquet J, Khaltaev NG, Cruz AA; World Health Organization. Global surveillance, prevention and control of chronic respiratory diseases: A comprehensive approach. World Health Organization, 2007. https://www.who.int/gard/publications/GARD Manual/en/ (accessed 22 February 2020).
4. Meghji J, Mortimer K, Agusti A, et al. Improving lung health in low-income and middle-income countries: From challenges to solutions. Lancet 2021;397(10277):928-940. https://doi.org/10.1016/ countries: From challenges

5. Soriano JB, Kendrick PJ, Paulson KR, et al. Prevalence and attributable health burden of chronic Soriano JB, Kendrick PJ, Paulson KR, et al. Prevalence and attributable health burden of chronic
respiratory diseases, 1990 - 2017: A systematic analysis for the Global Burden of Disease Study 2017. respiratory diseases, 1990 - 2017: A systematic analysis for the Global Burden of Disease

6. Lancet Respir Med 2020;8(6):585-596. https://doi.org/10.1016/s2213-2600(20)30105-3
6. Ahmed R, Robinson R, Mortimer K. The epidemiology of noncommunicable respiratory disease in sub-Saharan Africa, the Middle East, and North Africa. Malawi Med J 2017;29(2):203-211. https:// doi.org/10.4314/mmj.v29i2.24

7. Statistics South Africa. Mortality and causes of death in South Africa, 2016: Findings from death notification. Statistical release P0309.3. Pretoria: Stats SA, 27 March 2018. https://www.statssa.gov.za/ publications/P03093/P030932016.pdf

8. Meghji J, Lesosky M, Joekes E, et al. Patient outcomes associated with post-tuberculosis lung damage in Malawi: A prospective cohort study. Thorax 2020;75(3):269-278. https://doi.org/10.1136/ thoraxjnl-2019-213808

9. Osman RK, Mortimer K, Bjune G, El Sony AI. Chronic respiratory disease in adults treated for tuberculosis in Khartoum, Sudan. Public Health Action 2016;6(3):199-204. https://doi.org/10.5588/ pha. 16.0030

10. Allwood BW, van der Zalm MM, Amaral AFS, et al. Post-tuberculosis lung health: Perspectives from the First International Symposium. Int J Tuberc Lung Dis 2020;24(8):820-828. https://doi.org/10.5588/ ijtld. 20.0067

11. World Health Organization. Annex 2: Country profiles for 30 high TB burden countries. Global Tuberculosis Report 2019. https://www.who.int/tb/publications/global_report/tb19_Report_country_ profiles_15October2019.pdf (accessed 2 March 2020).

12. Jones R, Kirenga BJ, Katagira W, et al. A pre-post intervention study of pulmonary rehabilitation for adults with post-tuberculosis lung disease in Uganda. Int J Chron Obstruct Pulmon Dis 2017;12:35333539. https://doi.org/10.2147/copd.s146659

13. Desalu OO. Seasonal variation in hospitalisation for respiratory diseases in the tropical rain forest of South Western Nigeria. Niger Postgr Med J 2011;18(1):39-43.

14. Desalu OO, Ojo OO, Busari OA, Fadeyi A. Pattern of respiratory diseases seen among adults in an emergency room in a resource-poor nation health facility. Pan Afr Med J 2011;9(1). https://doi. org/10.4314/pamj.v9i1.71199

15. Tygerberg Hospital. FC2 Afrikaans pamphlet. 2016. https://www.westerncape.gov.za/assets/departments/ health/tygerberg_hospital_information_pamphlet___2016.pdf (accessed November 2020).

16. Western Cape Government. District/provincially aided hospitals. 2021. https://www.westerncape.gov. Western Cape Government. District/provincially aided
za/directories/facilities/914 (accessed December 2020)

17. Western Cape Government. Circular H 102/2020. Population Data. June 2020. https://www. westerncape.gov.za/assets/departments/health/h_102_2020_covid-19_population_data.pdf (accessed January 2021).

18. Buist AS, McBurnie MA, Vollmer WM, et al. International variation in the prevalence of COPD (the BOLD Study): A population-based prevalence study. Lancet 2007;370(9589):741-750. https://doi. org/10.1016/s0140-6736(07)61377-4

19. Varmaghani M, Dehghani M, Heidari E, Sharifi F, Moghaddam SS, Farzadfar F. Global prevalence of chronic obstructive pulmonary disease: Systematic review and meta-analysis. East Mediterr Health J 2019;25(1):47-57. https://doi.org/10.26719/emhj.18.014

20. Dreyer R, Viljoen AJ. Evaluation of factors and patterns influencing the 30-day readmission rate at a tertiary-level hospital in a resource-constrained setting in Cape Town, South Africa. S Afr Med J 2019;109(3):164-168. https://doi.org/10.7196/SAMJ.2019.v109i3.13367

21. Boum Y, Atwine D, Orikiriza P, et al. Male gender is independently associated with pulmonary tuberculosis among sputum and non-sputum producers people with presumptive tuberculosis in Southwestern Uganda. BMC Infect Dis 2014;14(1):1-8. https://doi.org/10.1186/s12879-014-0638-5

22. Quaife M, Houben RMGJ, Allwood B, et al. Post-tuberculosis mortality and morbidity: Valuing the hidden epidemic. Lancet Respir Med 2020;8(4):332-333. https://doi.org/10.1016/s2213-
the the hidden epide

3. Burney P, Patel J, Minelli C, et al. Prevalence and population attributable risk for chronic airflow obstruction in a large multinational study. Am J Respir Crit Care Med 2021;203(11):1353-1365. https:// doi.org/10.1164/rccm.202005-1990o

24. Quigley N, Gagnon S, Fortin M. Aetiology, diagnosis and treatment of moderate-to-severe haemoptysis in a North American academic centre. ERJ Open Res 2020;6(4). https://doi. org $/ 10.1183 / 23120541.00204-2020$

25. Abdulmalak C, Cottenet J, Beltramo G, et al. Haemoptysis in adults: A 5-year study using the French nationwide hospital administrative database. Eur Respir J 2015;46(2):503-511. https://doi. org/10.1183/09031936.00218214

26. Boachie MK, Ross H. Determinants of smoking intensity in South Africa: Evidence from township communities. Prev Med Rep 2020;19:101099. https://doi.org/10.1016/j.pmedr.2020.101099

27. Fidler-Benaoudia MM, Torre LA, Bray F, Ferlay J, Jemal A. Lung cancer incidence in young women vs. young men: A systematic analysis in 40 countries. Int J Cancer 2020;147(3):811-819. https://doi. vs. young men: A sy

28. To T, Stanojevic S, Moores G, et al. Global asthma prevalence in adults: Findings from the crosssectional world health survey. BMC Public Health 2012;12:204. https://doi.org/10.1186/1471-2458$12-204$

Accepted 28 July 2021 